\title{
Cognitive Approaches to Foreign Policy Analysis
}

Aaron Rapport

Department of Politics and International Studies

University of Cambridge

\section{SYNOPSIS:}

Cognitive theory encompasses mental activities such as the observation of different stimuli in an environment; the memorization and recall of information; pattern recognition and problem representation; and complex activities like social judgments, analytic reasoning, and learning. Cognitive psychology also highlights the constraints that prevent individuals from acting as utility-maximizing, fully rational decision-makers. These constraints lead people to rely on a regularly occurring set of cognitive mechanisms to simplify the decision-making process.

Scholars of foreign policy have drawn from several prominent areas of cognitive psychology to inform their research. One such area looks at the beliefs and belief systems that are the building blocks for most judgments. Researchers have also examined how actors use cognitive biases and heuristics to cope with uncertainty, which is abundant in foreign policy settings. An important set of cognitive mechanisms examined in foreign policy analysis (FPA) relates to judgments about policy risks and costs. Factors which facilitate and inhibit learning are crucial for understanding the conditions under which such judgments may improve over time. No cognitive process operates in a vacuum, but instead are moderated by an individual's group context and emotions.

There are several challenges in applying cognitive theory to FPA. Such theories are biased toward populations that are western, educated, industrialized, rich, and democratic. They are usually first tested using controlled experiments that measure group-level differences, whereas FPA scholars are often interested in the cognitive processes of individual leaders operating in chaotic environments. Individual-level psychological mechanisms may augment or offset one another, as well as interact with variables at the governmental, societal, and international levels of analysis in unpredictable ways. In light of these challenges, FPA scholars who employ cognitive psychology may wish to conceive of their enterprise as a "historical science" rather than a predictive one.

KEYWORDS: Biases, bounded rationality, cognition, decision-making, foreign policy, groupthink, heuristics, operational codes, poliheuristic theory, prospect theory. 
Cognitive theory focuses on how individuals and small groups engage in decisionmaking processes. Hudson (2005, p. 10) goes so far as to assert that "It is in the cognition and information processing of an actual human agent that all the explanatory levels of FPA [foreign policy analysis] are in reality integrated." This chapter outlines the core features of cognitive theory, as well as some important caveats about using this body of theory to explain foreign policy behavior. Much of it is devoted to the discussion of major research streams within cognitive FPA, though as a general overview it cannot provide an exhaustive summary of any of the expansive areas of cognitively-oriented research. The main purpose of the chapter is to critically assess several issues associated with an emphasis on human cognition as an explanatory framework for political decision-making. It concludes by discussing methodological confounders that can complicate the application of cognitive theory to FPA.

\section{Defining Characteristics of Cognitive Approaches}

Theories of cognition are concerned with how people attend to, process, store, and recall information (Simon 1985, p. 295). Seminal works by Snyder, Bruck, and Sapin (1962), Sprout and Sprout (1965), and Kelman (1965) departed from Freudian psychoanalytic theories of foreign policy that emphasized unconscious drives as motivations for behavior (Lasswell, 1930; George and George, 1956). Attempts to apply psychoanalysis to foreign policymakers often featured imprecisely formulated theories and considered certain policies to be irrational a priori, making it difficult to derive testable hypotheses or generalize beyond the particular individuals being studied. Conversely, researchers in cognitive psychology typically ascribe to positivist theory and aspire to use scientific methods to derive law-like, falsifiable, general theories of human decision-making. 
Cognitive approaches to FPA usually assume that people are procedurally rational, but there are clear divergences between this "bounded" rationality and the "substantive" variety (March, 1978; Simon, 1972; Simon, 1985, p. 294). Substantive rational-choice approaches assume that decision-makers have stable, ordered preferences; use all relevant and available information; carefully weigh the probability of different events and the utility of all possible outcomes; and update their beliefs in a systematic fashion when presented with new evidence to arrive at an optimal decision (Lau and Levy, 1998, p. 30). Conversely, procedural rationality presumes that limited cognitive capacities that prevent people from processing information, weighing probabilities, fully specifying available policy options, and learning from events in an optimal manner. Individuals do the best they can to make policy choices given these constraints, but they rarely maximize utility when making decisions. Instead decision-makers satisfice, meaning they choose policies judged to be "good enough" even if further analysis of a problem could lead them to a policy of greater value (Hafner-Burton, Hughes, and Victor, 2013, pp. 370, 372; Mintz, 2007, p. 158; Rosati, 2000, pp. 50, 52-53). It is possible for decision-makers to overcome some cognitive constraints by exerting more mental effort. However, they also face physical constraints, such as the limited amount of information humans can store in their working memory at any given time.

Another theme of cognitive theory is that individuals seek to maintain consistency and avoid the dissonance that arises when different beliefs conflict with one another (Festinger, 1957). The mind processes information in such a way that it creates the impression of an ordered reality, instead of what William James (1981 [1890], p. 462) called the "blooming, buzzing confusion" stemming from the complexity of the stimuli present in individuals' social and natural environments (similarly see Goldgeier and Tetlock, 2001, p. 83; Rosati, 2000, p. 52). 
People impose structured narrative accounts on events that may be more accurately described as random or haphazard (Hammack and Pilecki, 2012; Patterson and Monroe, 1998). Individuals are thus prone to attend to information that they expect or are primed to see, effectively confirming their pre-existing beliefs while neglecting or discounting discrepant information (Jevis, 1976, ch. 4; Vertzberger, 1990, ch. 3).

Hudson (2005, p. 3) is largely correct in her assertion that FPA is "profoundly actorspecific," meaning that different leaders are likely to choose divergent policies even when faced with similar problems and scenarios (Byman and Pollack, 2001; Hermann, Preston, Korany, and Shaw, 2001; Jervis, 2013). It is true that cognitive processes and personality traits will vary throughout a population. However, cognitive theory typically assumes that psychological traits will be distributed such that, on average, one can expect certain mental processes to be characteristic of most individuals. Cognitive research has found that "people select information about alternatives and combine it into choices in systematic ways" that are "predictable" (Lau and Levy, 1998, p. 31), which contributes to an emphasis on actor-generality. Nevertheless, most psychology studies involve participants from WEIRD states: countries that are Western, Educated, Industrialized, Rich, and Democratic. Furthermore, individuals from the United States make up a disproportionate number of participants in psychology experiments and FPA studies, and may be outliers even amongst their WEIRD counterparts (Henrich, Heine, and Norenzayan, 2010; Hermann, 2001, p. 49; Rosati, 2000, p. 71). ${ }^{1}$ This hinders the use of cognitive theory to generalize about foreign policy decisions and behavior.

\footnotetext{
${ }^{1}$ Thus, when this chapter states something like "people generally..." one should presume such statements are based largely on studies of the cognition of WEIRD people.
} 


\section{Major Areas of Cognitive FPA}

Cognitively-oriented researchers doing FPA have made contributions to many areas of the field (Mintz, 2007, p. 160). Of these, five are addressed here. The first is research into how foreign policy decision-makers think of themselves, others, and the practice of politics. The second involves studies of cognitive biases and heuristics that affect how political actors reason about information. The most prominent work in this area, addressed in the third section, has been research into how decision-makers calculate the expected risks, costs, and benefits of their

policy actions. Fourth is research into whether and how policymakers learn. Lastly, the chapter examines how group context and emotion can moderate cognitive processes.

\section{Beliefs, Identities, and Images}

Beliefs are persistent ideas an actor holds describing the way the world works (causal beliefs) as well as what constitutes appropriate or legitimate conduct (normative beliefs; Jervis 2006, pp. 642-643). Along with affect and behavior, they are a component attitudes, or evaluations of "a particular entity with some degree of favor or disfavor" (Eagly and Chaiken, 1993, p. 1). They are less broad than values, which act as general guides that are less contextspecific than beliefs or attitudes (Rokeach, 1973). Belief systems, or the associated term "cognitive maps," are cognitive structures that detail the causal and normative relations between different concepts that constitute beliefs, with those of primary importance to a decision-making context being invoked more frequently than connected but peripheral beliefs (Axelrod, 1976;

Larson, 1994, p. 20).

A prominent area of FPA is research on leaders' beliefs in the form of "operational codes" (Leites, 1951; George, 1969). Stressing policymakers' cognitive limitations, George 
hypothesized that leaders regularly drew from a set of five "instrumental" and five "philosophical" beliefs in order to simplify the decision-making process, establish policy options, and choose amongst them. Instrumental beliefs specify "ends-means relationships," or causal mechanisms a policymaker thinks link decisions, actions, and outcomes. Alternatively, philosophical beliefs establish a decision-maker's views on the "fundamental nature of politics," such as whether it is primarily characterized by conflict or cooperation (George, 1969, pp. 199200). Both types of beliefs are stable, though they can change as leaders learn from experience (George, 1969, pp. 216-220; Renshon, 2008).

Operational code theory does not hold that the limited set of beliefs George detailed constitute the whole of policymakers' ideas about the political realm. Indeed, among many possible examples, other scholars have detailed beliefs about whether threats typically arise from other countries' foreign policies or domestic institutions (Saunders, 2011); whether leaders' beliefs about domestic policy are associated with those concerning foreign policy (Rathbun, 2007); and the effects of military experience on leaders' beliefs and policies regarding the use of force (Horowitz and Stam, 2014). Furthermore, there is considerable variation across different leaders in terms of their instrumental and philosophical beliefs, and in that regard operational code theory recognizes a degree of actor-specificity. However, operational code research also assumes that the same ten instrumental and philosophical categories are central and applicable to numerous leaders' belief systems (Walker, Schafer, and Young, 1998, p. 176), even though beliefs within these categories vary from person to person.

Computer-assisted content analysis of policymakers' speeches and other communications enables researchers to analyze a large amount of data and maximize inter-coder reliability and content validity (Schafer, 2000; Walker, Schafer, and Young, 1998). Quantitative measurements 
of different beliefs can be used as variables in statistical models to estimate the effects of his or her beliefs on the propensity to use force, apply sanctions, and so forth (Schafer and Walker, 2006). This approach does not account for contextual specificity, or the possibility that the same words may have different meanings across time and space (Adcock and Coller, 2001, pp. 534536). Even though Leites (1951) developed the operational code to analyze beliefs of Soviet leaders, its developmental trajectory leaves its validity beyond the WEIRD context in a state of greater uncertainty.

Closely related to beliefs are individuals' images of those outside their own political communities, and how these affect people's conceptions of themselves and their social groups. Images are cognitive schemata, which like belief systems consist of a person's "interrelated knowledge about a concept or stimulus" and are structured hierarchically from general to more specific (Larson, 1994, pp. 19-20). For example, one may possess an image of “dictators" characterized by linked characteristics (authoritarian, aggressive, etc.) into which specific leaders, such as Adolf Hitler, fit. As with beliefs, images are simplified versions of their referents. Racial stereotypes are a well-known type of prejudicial image that can also affect foreign policy decisions (Hemmer and Katzenstein, 2002).

Images are in part produced and sustained by an individual's cultural milieu (Bar-Tal and Teichman, 2005; Jahoda, 1999). They are also affected by individual-level psychological mechanisms. For example, if there are multiple possible images of another political community, as will typically be the case, people's need for self-esteem may lead them to adopt a less flattering image of the outgroup to highlight their own perceived superiority (Herrmann, 1985, p. 672). Attribution theory indicates that political leaders will ascribe adversaries' and allies' undesirable actions to the latter groups' own inherent resoluteness or lack thereof, respectively. 
This has significant implications for the importance of reputation for resolve, a subset of leaders' overall images of other states, in international politics (Mercer, 1995).

Given the massive stakes of international conflict in the nuclear era and the potential consequences of misperception during crises, Cold War-era researchers intensely examined Soviet and U.S. leaders' images of one another (Herrmann, 1985; 1986; Holsti, 1962). In general, members of WEIRD societies are biased toward attributing other people's actions to their personal traits rather than situational pressures, a predisposition called the fundamental attribution error (Ross, 1977). This can give rise to or reinforce images of other individuals' perceived groups, as well as reinforce dangerous patterns of international relations. For instance, if state leaders are more likely to attribute one another's decisions on military spending as signs of an innately hostile character rather than systemic pressures to defend their country, this will exacerbate the security dilemma (Glaser, 1997, p. 182).

Jervis (1970) notes that the images adversaries project at one another, and the inferences opponents draw as a result, are crucial for understanding conflict dynamics. State leaders trying to estimate whether their opponent has defensive or aggressive intentions must evaluate whether or not their adversary's words and actions decidedly place them in one of these two categories. Information that allows a decision-maker to differentiate opponents along these lines may be a "costly signal" (Schelling, 1966, p. 150) in that certain images are too costly to project unless the sender is sincere - otherwise the cost of sending the signal would outweigh the gains sought. However, variations in individuals' prior expectations and images of an adversary will lead different actors to draw dissimilar conclusions about an action's meaning. Even if one side makes a statement it considers "cheap talk," in that they do not believe it will affect their opponent's perception of them, leaders on the other side may significantly change their estimates 
of the adversary (Hall and Yarhi-Milo, 2012; Mercer, 2013; Yarhi-Milo, 2014).

Per constructivist International Relations (IR) theory, images can be co-constitutive (Wendt, 1998), meaning the structure of one's schema of the "other" is fundamental for understanding oneself and vice versa. This perspective is most prominent within cognitive FPA on role theory. Roles are relational identities. For example, it makes no sense to see one's state as "leader of the free world" if one has no image of what the "followers" in the "free world" are like. Holsti (1970) argued that countries had numerous "national role conceptions" that described these ideas of self and other. Along with scripts for behavior, roles can also define where one stands in the international hierarchy. The behavioral scripts and status-conscious dimensions of roles combine to inform foreign policy choices. For instance, if state leaders adopt a hostile, oppositional role conception while simultaneously believing their country has not risen to its proper station in international politics, they may be more apt to pursue nuclear weapons than a comparable country in which satisfied and non-oppositional role conceptions nevertheless predominate (Hymans, 2006).

The question of which image or role will be salient at any given moment is not a minor one. Holsti (1970, p. 260) identified 17 different national role conceptions, which other researchers elaborated upon and extended (Walker, 1987; Le Prestre, 1997). In cases where a multitude of images and identities are available, outside factors must be incorporated into the theoretical framework to predict which will rise to the fore. Institutional context and bureaucratic politics may be especially important in determining the officials who constitute the "ultimate decision-making unit" (Hermann and Hermann, 1989) and thus which role conceptions and images they favor. Research from the field of American Politics demonstrates that threat perceptions are likely to make negative images of outgroups particularly salient (Marcus, 
Sullivan, Theiss-Morse, and Wood, 1995). If people fear for their own survival they are also likely to reject novel roles, instead being drawn to those highlighting traditional behaviors, beliefs, and values (Greenberg, Solomon, and Pyszczynski, 1997).

\section{Heuristics}

Beliefs, images, and roles, which are themselves simplified representations of reality, may in turn be produced by cognitive processes that are simpler than those involved in substantively rational decision-making. These processes are forms of heuristic reasoning, or mental shortcuts. Heuristics privilege certain types of information over others to make evaluations or determine a course of action, even if the excluded information is relevant to the decision in question. Kahneman and Tversky (1974) documented numerous cognitive heuristics people use when faced with uncertainty. Someone using the representativeness heuristic, for instance, attends to stereotypical characteristics of an entity in order to judge the probability it belongs to a certain category. Say someone is asked the probability that a political leader is a dictator versus the probability that leader is a dictator and a communist. A person reliant on the representativeness heuristic whose stereotypical image of a dictator is a communist like Mao, rather than a right-wing dictator like Pinochet, would say the latter probability is higher. This would be an incorrect answer, but because most people are unfamiliar with the rules of conditional probabilities, it is simpler to use the heuristic to arrive at a conclusion.

Heuristics are a biased form of information processing, used because a full assessment of all relevant evidence in a decision-making context is often beyond a person's cognitive capacities. Heuristics are more likely to be used if there is very little time to make a decision, or multiple problems must be addressed simultaneously (Rieskamp and Hoffrage, 2008; Sweller, 
1988). Nevertheless, heuristic reasoning can approximate substantive rationality, especially for experts who can base decisions on patterns they recognize from past experiences. Even if a chess grandmaster cannot calculate all possible moves given the position of pieces on the board, she may recall numerous games in which the configuration of pieces resembled that of the current match and accordingly outline a non-exhaustive set of effective strategies. Likewise, though political experts may not do well at predicting international events or learning from past errors (Tetlock, 2005), they do appear better able than non-experts to use heuristics to prioritize information when addressing specific problems, which also serves to streamline the advisory process and allows officials to reach decisions in a more efficient manner (Hafner-Burton et al., 2013; Hermann, 1986; Saunders, forthcoming).

The poliheuristic model (Mintz and Geva, 1997) tries to account for a multiplicity of mental shortcuts decision-makers use, and has been applied to a wide array of foreign policy issues (Mintz, 2004, pp. 4-6). Each option for dealing with a foreign policy problem can be evaluated along multiple dimensions: military feasibility, economic consequences, likelihood of public support, and so on. The poliheurstic model theorizes a two-step decision process that begins with an individual eliminating certain options in a non-compensatory manner. This means that, rather than engaging in a substantively rational cost-benefit analysis of each option in which a weakness along one dimension can be compensated for by strengths associated with another (e.g. option A has high military costs but will likely receive popular support), weaknesses along a particularly salient dimension of a policy option might not be offset by strengths of the option's other dimensions no matter how great they are. ${ }^{2}$ As an example, Farnham (2000) argues that President Franklin Roosevelt judged foreign policies primarily by

\footnotetext{
${ }^{2}$ Because people satisfice, the order in which alternative policies are presented also matters. An option that is minimally satisfactory along all critical dimensions is likely to be retained for further evaluation if presented first, but might not if it is preceded by several other options that are similar or even slightly worse.
} 
whether he could secure public support for them. If he did not believe support would be forthcoming, he would not consider the option or its other attendant dimensions any further. In fact, the most common cognitive shortcut is to evaluate whether or not an action will damage a policymaker's own political fortunes (Mintz, 2004, p. 7). Once a policymaker has simplified the decision-making process by limiting the number of acceptable choices, the remaining ones are evaluated in a more substantively rational manner.

Poliheuristic theory has been criticized for not explaining how political actors define foreign policy issues as "problems" that must be addressed $;^{3}$ over-emphasizing the salience of political considerations compared to other policy dimensions; and neglecting the institutional context in which decisions are made (Stern, 2004, pp. 110-111). Poliheuristic theory has been applied to leaders in the Middle East and South Asia as well as FPA's typical emphasis on the decisions of U.S. politicians (Mintz, 2004, p. 6), which somewhat deflects the critique regarding the neglect of institutional context and avoids generalizations based solely on WEIRD states. Another criticism of the poliheuristic theory is its assumption that rational actors are risk averse. In the second stage of the model, decision-makers are presumed to rationally select the policy option that "maximiz[es] benefits and minimiz[es] risks" (Mintz, 2004, pp. 6-7). However, a tendency to take big gambles when making decisions is not necessarily irrational, but may simply be considered a preference like any other. Furthermore, research using other cognitive models has shown that an individual's preference for risk is often contingent on the situation and the type of heuristics they employ, a subject to which the chapter now turns.

\section{Risk, Loss, and Overconfidence}

Risk is formally defined as the variance of outcome values in a probability distribution,

\footnotetext{
${ }^{3}$ On problem representation in foreign policy, see Sylvan and Voss (1998).
} 
such that policy options become riskier as the range of their possible outcomes increases. The common understanding of the term simply associates risk with the potential for bad outcomes. What is more, there will often be a difference between the real risks involved in a policy scenario and the risks decision-makers perceive, which will be a function not only of the variance and magnitude of potential outcomes, but also the amount of confidence individuals have in the information upon which their decisions are based (Vertzberger, 1998). Despite findings that indicate political actors would normally be risk averse (Baumeister, Bratslavsky, Finkenauer, and Vohs, 2001), instances in which decision-makers have been overconfident have also been thoroughly studied by FPA scholars. Heuristics can be a source of unjustified optimism.

Prospect theory details how individuals become more willing to take risks when in the "domain" of loss, and more cautious when in the domain of gains (Kahneman and Tversky, 1979b; McDermott, 1998; Mercer, 2005). This is true even when logically equivalent scenarios are framed differently to make losses more salient than gains or vice versa. The best known example of this is Kahneman and Tversky's (1984) experiment in which participants were given a choice of two policies to address a hypothetical outbreak of disease. Some participants were told that if they chose Policy A, 400 of 600 sick people would die, whereas if they chose Policy B there was a one-third chance all 600 people would be saved and a two-thirds chance no one would be saved. Other participants were told Policy A would kill 200 of 600 people; the probabilities attached to the different outcomes possible under Policy B remained the same. Policies A and B have the same expected results, but Policy B is the riskier option as probability comes into play. ${ }^{4}$ Risky Policy B was preferred by a majority of people when Policy A was

\footnotetext{
${ }^{4}$ Prospect theory also details how people's evaluations of probabilities vary depending on how great or small they are. Individuals tend to overweight small probabilities as well as very high probabilities, such that changes in probabilities near 0 or 1 have a larger impact on people's preferences for risk than do mid-range probabilities (Levy, 1992, p. 178).
} 
framed as producing a loss (killing 200 people instead of saving 400), but the certainty of Policy A was preferred when it was framed as a gain (saving 400 instead of killing 200).

Prospect theory has numerous implications for FPA scholars. Among these, leaders of declining powers may be expected to be more risk-acceptant in their decision-making than leaders of rising states. Deterrence should also be easier than compellence: the former requires a challenger to forgo a gain, whereas the latter requires states to accept a loss. However, one difficulty in applying prospect theory to foreign policy is that whether a political actor is in a domain of gain or loss depends on their "reference point" (Levy, 1992, pp. 176-177). Consider the hypothetical leader of a state that lost a piece of territory years ago. If the leader's reference point is the time period prior to this loss, prospect theory would expect him to be risk-acceptant and take aggressive action to retake the former possession. However, if the leader's reference point is the present, it is more plausible that he would be risk-averse, as acquiring the territory would represent a gain over the status quo. Whereas psychologists can establish participants' reference point during an experiment, the same cannot be said for FPA scholars studying historical cases of political decision-making.

A related challenge for prospect theory is that the theory acknowledges that one's reference point may lie in the present, past, or future, but does not take into account how that point's temporal distance from the present matters (Krebs and Rapport, 2012). Studies have shown that people do not discount losses or gains at a constant rate. Instead, both-but especially gains - lose their subjective value more rapidly than standard discounted utility theory would expect as they become further removed from the present. Conversely, as losses and gains become quite temporally distant, they virtually cease declining in subjective value. This "hyperbolic" form of discounting, where values decline rapidly in the near-term and then plateau 
in the long-term, can lead to irrational reversals of policy preferences and make cooperation between states harder to achieve than rational-institutionalist models of IR would suggest (Streich and Levy, 2007).

When future losses and gains are probabilistic rather than certain, as is usually the case in international politics, individuals tend to be overconfident in their plans to secure goals in the more distant future in comparison to those meant to accomplish day-to-day tasks (Johnson, 2004, pp. 41, 237). To effectively assess one's future plans, it is necessary to evaluate both the probability of a plan's success and the magnitude of the benefits sought (or losses avoided). However, the further in the future one expects to achieve a goal and execute part or all of one's plan, the harder it is to envision the contextual features that will affect the probability of its success. One might think this would lead to pessimism, but Kahneman and Tversky's (1979a) study of the "planning fallacy" found the opposite: temporal distance usually led people to underestimate the costs of attaining their goals or completing a task, even if they had experienced difficulty with similar tasks in the past. According to construal level theory (Trope and Liberman, 2003), this is because people employ a heuristic when evaluating long-term plans. Instead of exerting cognitive energy assessing their plan's feasibility, they simplify their assessments by concentrating on the desirability of their goal, which is much less dependent on future contextual details. They thus construe their actions in terms of why they are pursuing their high-level goals, rather than how they are going to formulate and execute the concrete steps of their plan. This abstract, high-level focus leads people to neglect or ignore how unexpected events and other factors that generate risk could affect their plan's feasibility. This has implications for how state leaders think about addressing future threats or seizing distant 
opportunities (Krebs and Rapport, 2012), as well as how they assess combat versus post-conflict tasks in war (Rapport, 2015).

\section{Learning and Foreign Policy}

Learning may be the most complex of all cognitive activities. It involves the categorization of a current event as a puzzle or problem; identification of the fundamental features of the problem based on existing beliefs and schemas; retrieval of information regarding past events; the organization of that information in such a way that it can be applied to the current event; and observation of the effects of one's own or another's actions that are then used to update causal and/or normative beliefs. Learning is often done "on the fly" through trial-anderror as an individual executes strategies to solve a puzzle and then adjusts based on the feedback they receive, sometimes redefining the problem at hand (Levy, 1994; Stein, 1994; Hermann, 1990).

Foreign policy is an especially difficult area in which to learn and apply lessons. Most political problems are "ill-structured" in that they have no single solution (Hermann, 1990, p. 10; Levy, 1994, p. 292; Stein, 1994, pp. 172-173). Not only do policymakers typically lack a great deal of relevant information, but they may not even be aware of what pieces of information they are lacking (those infamous "unknown unknowns"). The very definition of learning is conceptually fraught in that scholars disagree about whether or not it necessarily involves an increase in the accuracy and precision of beliefs (Stein, 2002), or simply requires cognitive change in response to some external stimuli (Levy, 1994; Reiter, 1996).

A prominent area of the FPA literature studies how policymakers use historical analogies to learn and make decisions. This as both "causal" and "diagnostic" learning (Levy, 1994, p. 
285): past experiences inform present estimates of what the outcome of different policy actions will be, and are used to identify key features of the current situation. Leaders typically overgeneralize from past events, obscuring differences between historical cases and the ones at hand (Khong, 1992; Neustadt and May, 1986; Vertzberger, 1986). Khong (1992, p. 7) models analogous reasoning as $A X: B X:: A Y: B Y$, meaning that if event $A$ had attribute $X$ and event $B$ also has $X$, a policymaker infers that since $A$ had attribute $Y$ then $B$ also has $Y$. For example, Khong argues that U.S. officials who subscribed to the "Dien Bien Phu" analogy before the Vietnam War reasoned that because French military efforts against the Viet Minh had resulted in prolonged fighting and defeat, ongoing U.S. military efforts would also fail. Alternatively, policymakers using the "Munich" analogy (referring to the deal struck with Hitler in 1938) had learned that appeasing hostile forces leads to further aggression, with countries falling like "dominoes" as the adversary presses its military campaign forward. ${ }^{5}$ They were thus much more in favor of U.S. military action in Vietnam.

Over-generalization is just one impediment to accurate and efficient learning. Instead of neutrally applying evidence to learn about existing theories, people use numerous heuristics and rationalizations to sort information (Tetlock, 1999). Their beliefs thus change more slowly than a substantively rational model would expect. ${ }^{6}$ Foremost amongst these heuristics is the confirmation bias: people search for and attend to evidence that supports their existing worldview rather than that which would challenge it (Nickerson, 1998). Another inhibitor is the hindsight bias (Fischhoff, 1975). Once people know the outcome of a case, such as whether a given foreign policy succeeded in attaining its goals, they retroactively interpret the evidence

\footnotetext{
${ }^{5}$ Saying states are dominoes waiting to be toppled is metaphorical reasoning, which is related to the analogous form (Shimko, 1994).

${ }^{6}$ One model of rational learning is based on Bayes Law. Confidence in a belief is established by accounting for one's prior confidence in that belief and the likelihood that one would observe a specific outcome (such as an adversary behaving more aggressively after being appeased) if the belief was correct.
} 
such that the outcome seems virtually inevitable. The hindsight bias can lead those who make correct predictions overconfident in the theory underlying their estimates, since they neglect how uncertain they were prior to the outcome being observed. Scholars of covert intelligence keenly note how political leaders use hindsight to blame surprise attacks or disappointing policy outcomes on intelligence "failures" even if there was no realistic way such events could have been predicted (Pillar, 2011, p. 228).

Scholars have also explored individual-level factors that promote or inhibit learning. In his study of U.S. foreign policy toward Latin America, Etheredge (1985) argued that policymakers failed to learn effectively because they typically had a "hardball" personality type. Harkening back to psychoanalytic theories, Etheredge contends that hardball politicians' insecurities and their need to demonstrate social dominance led them to resist compromise and favor coercive actions designed to undermine leftist governments regardless of the past outcomes of such policies. Twenty years later, Tetlock (2005) highlighted a different aspect of policy experts' personalities, drawing from Isaiah Berlin's metaphor of "foxes" and "hedgehogs." Foxes rely less on general theories to understand how the world works and instead are open to multiple explanations for why any given foreign policy outcome occurred. As a corollary, they are apt to treat each foreign policy problem as unique. Conversely, hedgehogs deduce likely foreign policy outcomes and events from an overarching theory; they know "one big thing" which they use to understand the world. Tetlock's multi-year study of foreign policy experts' predictions about international events revealed that foxes were considerably better at the task, and were more effective at updating their beliefs after mistaken predictions than were hedgehogs. These findings support related studies on the association between theories, cognitive complexity, 
and learning (Hermann and Choi, 2007; Koopman, Snyder, and Jervis, 1990; Suedfeld and Tetlock, 1977).

Along with personality, FPA scholars have emphasized how contextual factors affect the learning process. Drawing from research in neuroscience, Holmes (2013) argues that face-toface meetings between diplomats and foreign leaders enable greater learning than less direct forms of communication. Directly observing another's expressions during talks activates "mirror neurons" in the brain which simulate the mental processes of one's conversation partner. In other words, face-to-face meetings better allow people to understand what their interlocutor is thinking. Communicative expressions that are automatic and involuntary act as "indices", which unlike "signals" are determinative rather than probabilistic indicators of another's beliefs (Jervis, 1970).

Aside from applications of the life sciences to FPA work, social features like accountability have been argued to promote learning. If an individual believes they will face significant consequences depending on how well they analyze a problem, they are likely to expend more effort searching for relevant information and be more critical when evaluating it (Tetlock, 1985). Stern (1997) asserts that foreign policy crises probably induce greater accountability, as a large portion of political leaders' constituencies will be attentive to how policymakers perform when the stakes are high. At the same time, Stern (1997, p. 77) correctly notes that too much stress can inhibit learning, a point made elsewhere (Hammond, 2000; Lebovic, 1995, p. 845). Given this caveat, it is important to distinguish between learning during and after a crisis. During a crisis, decision-makers' responses to stress may partially cancel out the positive effect accountability has on learning. Afterwards, leaders may have the time to more 
thoroughly reflect on what lessons they should take away, but depending on the crisis outcome may feel less accountable to public scrutiny and unmotivated to evaluate their decisions.

Accountability may not be an unalloyed good. If leaders expect their decisions to be heavily scrutinized, they may think it is safer for them to agree with whatever consensus appears to emerge within a decision-making group. Such a strategy will diffuse responsibility across numerous decision-makers rather than focusing it on an individual whose position stood out from the rest, diminishing creativity and willingness to challenge the majority view in the process (Meade and Stasavage, 2008). Diffusion of responsibility can in turn lead decision-making groups to adopt more extreme positions, since blame for failure will not fall on any particular individual. This will especially be the case in democracies governed by coalitions, as shared responsibility will diffuse harm at the ballot box rather than concentrating it on a single party (Beasley and Kaarbo, 2014; Kaarbo, 2008, pp. 61-62).

\section{Key Moderators of Cognition: Group Context and Emotion}

These last points highlight the important effects group-level variables and emotions have on cognitive processes. Regarding the former, political decisions are rarely made by a single person. Two of the most influential works to promote the study of psychology in the context of political groups were Janis's (1972) research on “groupthink,” and Allison's (1971) conceptualization of bureaucratic politics. Both authors focus on episodes of U.S. foreign policy crises. Janis argues that ideologically homogenous groups often prized cohesion and concurrence above all else when addressing a problem. This is especially be the case under stressful conditions, such as foreign policy crises, since the perception of unanimity enhances each decision-makers' confidence in their group. As a corollary, groupthink discourages dissent 
and leads to poor decision-making: truncated information search and limited articulation of policy alternatives; reluctance to revisit earlier decisions or reconsider definitions of the problem; the adoption of simplistic, hostile images of outgroups; and so forth. Alternatively, the fundamental cognitive premise of Allison's model is that "where you stand is where you sit." In other words, the bureaucratic organizations individuals belong to significantly shape their preferences and definitions of the national interest. According to Allison, the U.S. government was not unitary during Cuban Missile Crisis, but rather a collection of competing bureaucratic actors bargaining and compromising with one another in order to arrive at a strategy.

Though still widely cited, both Janis's and Allison's models have been thoroughly criticized. Although there has been some empirical support for groupthink's hypothesized effects on foreign policy decisions (Herek, Janis, and Huth, 1987), most of the evidence has been mixed or contrary to the model's expectations (Fuller and Aldag, 1997; Kramer, 1998; Schafer and Crichlow, 2010; Tetlock, Peterson, McGuire, Chang, and Feld, 1992). Allison, meanwhile, was not wrong to assert that bureaucracies affect individual preferences and the way people mentally represent problems. Organizations and political groups influence what information individuals attend to by framing policy issues, systematically highlighting certain features of typical problems while obscuring others (Garrison, 2001; Maoz, 1990; Yarhi-Milo, 2014). By defining what counts as "success," bureaucracies also affect what information their members monitor when determining whether or not a policy is effective, as well as the adjustments they implement when goals are not being met (Gartner, 1999; Steinbruner, 1974). Nevertheless, Allison's model of bureaucratic politics has been criticized for its murky definitions of key concepts and for drawing conclusions that do not logically follow from its assumptions (Bendor and Hammond, 1992; Welch, 1992). 
Despite their flaws, these early works provided ground on which other researchers could build. Consistent with groupthink, decision-making groups were observed to engage in "risky shifts," adopting policies that were riskier than any individual group member preferred by themselves (Vertzberger, 1984, p. 73). However, continuing research found that groups in fact exhibit "polarization," meaning they adopt policies that are either riskier or more cautious than any individual member's preferences (Kaarbo, 2008, p. 60). The extremity of outcomes in different directions indicates the structure and composition of a group significantly moderates policymaking. It might be tempting to assert that foreign policy groups within democracies would be prone to shifts in a more cautious direction, as the multiple institutional checks and constituencies to which leaders are responsible would constrain behavior. This hypothesis, however, neglects the role that leaders play in group decisions. Hermann and Kegley (1995) posit that moderate leaders in democracies will act pragmatically, showing sensitivity to institutional constraints and flexibility in response to incoming information. Conversely, ideologically-driven leaders will aggressively try to circumvent constraints and be less apt to modify goals in the light of new evidence. ${ }^{7}$ Schafer and Crichlow (2010) provide qualitative and quantitative evidence showing that distrustful leaders are most likely to structure their decisionmaking groups so they are closed off from outside sources of information, often leading to higher levels of conflict with other states.

Charles Hermann and colleagues (Hermann, Stein, Sundelius, and Walker, 2001) further specify how a leader's orientation and the composition of the decision-making group interact. If members primarily identify with the decision-making group, as opposed to their bureaucratic agencies or other constituencies, and are led by an ideologue, collectively they are likely to

\footnotetext{
${ }^{7}$ This is consistent with Rathbun (2014), who finds that ideologically extreme leaders in democracies and non-democracies are less sensitive to domestic and foreign structural constraints when negotiating.
} 
exhibit many symptoms of groupthink. A pragmatic leader who encourages norms of dissent, however, can preclude such decision-making pathologies even within a tightly knit group. If members do not primarily identify with the group and require unanimity to arrive at a decision, the outcome may be deadlock or compromise depending on whether the leader is able to act as a broker. If a mere plurality of group members is required to adopt a policy, then the degree to which the decision reflects the views of the group will depend in part on how much encouragement the leader gives to minority preferences. This framework appears to provide explanatory leverage beyond the WEIRD domain (Beasley, Kaarbo, Hermann, and Hermann, 2001).

A commonly prescribed method of avoiding groupthink and polarization is "multiple advocacy" within decision-making groups (George, 1972). Multiple advocacy requires decisionmaking groups to be composed of members with diverse preferences and expertise such that no one perspective has a pronounced advantage over the others. Ideally all members are equally resourced and familiar with the foreign policy problem at hand, and the leader encourages a balanced debate within the group (George and Stern, 2002, pp. 491-493). By pooling expertise and affording each member's view equal representation, multiple advocacy is meant to approximate a substantively rational decision-making process. There are tradeoffs involved in such an approach, however. Multiple advocacy can take a greater than average amount of time to execute effectively compared to other processes. Another potential challenge is that, if the group leader is not mindful of encouraging group members to offer distinct perspectives, individuals may disproportionately share "common" information - that which was already known by most of the group members prior to discussion. Not only is common information often more prevalent than individuals' unique pieces of information, but people are perceived as 
more competent and credible when they put forward information that others already know (Stasser and Titus, 2003). During crises, when time is short, people will try to find consensus quickly, which will further encourage discussion of common information (Karau and Kelly, 1992).

The preceding discussion included observations about the role emotional stress can play in cognition. A wealth of new findings in regards to affect and cognition have cropped up in the past two decades, and the Political Science and IR disciplines have increasingly made emotion central to their agendas (Hall and Ross, 2015; McDermott, 2004; Mercer, 2010). ${ }^{8}$ Though individuals' emotional states do not always influence their cognitive processing, they are most likely to do so when people attend to problems that are complex and atypical (Forgas, 1995), which is characteristic of many foreign policy problems and crises.

One of the primary findings from research on emotion and cognition is that events and beliefs generally have an emotional "tinge" attached to them. Triggering an emotion attached to an event will make it more accessible in one's memory (Hermann and Choi, 2007, pp. 142-143), and if the emotional charge of the event is very strong it will be more likely to dominate an individual's decision-making (Stein, 1994, p. 169). Not all emotions affect cognition in the same way, however. People in positive moods are prone to act like hedgehogs, or rely on general knowledge structures to make inferences. Analogies, heuristics, and basic belief systems are all examples of this type of cognitive processing. Conversely, negative emotions promote fox-like thinking, or the use of inductive, case-specific reasoning. This may be because people in good moods are more confident in relying on familiar general knowledge structures, while people in bad moods infer there is something "not right" in their environment and thus are more attentive

\footnotetext{
${ }^{8}$ Many theorists distinguish between "emotion" and "affect," but for the sake of brevity both terms are treated as equivalent here.
} 
to situation-specific information (Bless, 2000). Relatedly, positive moods facilitate the assimilation of incoming information into existing knowledge structures. Negative moods, on the other hand, lead people to see situations as more unique while motivating them to avoid judgment errors and retain as much incoming information from the situation as possible (Fiedler, 2000).

Though the preceding makes it appear that negative emotions are more conducive to learning, it is important to remember that those with foreign policy expertise may be better able to utilize general knowledge structures to address problems than novices. Treating each situation as unique may not be particularly efficient. Furthermore, negative emotions like anxiety can either help or inhibit cognition depending on how strongly it is felt. For instance, people generally attend more to feasibility considerations when evaluating plans that will be executed in the near future, which guards against overconfidence. However, if an individual is feeling a great deal of stress because a calamitous event like a war appears imminent and unavoidable, they may cope with their emotions by entering an "implemental mindset" that spurs them to execute plans confidently rather than consider the costs and risks of doing so (Johnson and Tierney, 2011).

\section{Conclusion: Methodological Issues and Cognitive FPA as Science}

Despite the diversity of findings in cognitive psychology, this area of study is largely agreed on the fundamentals of human information processing. People are modelled as boundedly-rational information processors who satisfice and seek to maintain cognitive consistency in the face of a complex environment. With this basic model as a reference point, researchers have used scientific methods to try and establish generalizable theories about how 
people process and act upon information in different contexts. It has long been debated whether FPA and IR theory should ascribe to this mode of knowledge production, but even if one answers in the affirmative there are several methodological caveats to be aware of when applying cognitive theory to the study of politics.

Numerous authors have questioned whether findings in psychology obtained using controlled experiments are externally valid — can one infer the cognitive traits of foreign policy officials using results from "typical" individuals in an artificial setting (Hafner-Burton et al., 2013; Lau and Levy, 1998, pp. 40-41; Mintz, Redd, and Vedlitz, 2006)? This problem may be further confounded by the alleged "replication crisis" in psychology, in which researchers have debated the prevalence of problematic research practices that bring the reliability of a range of findings into question (Pashler and Wagenmakers, 2012; Simmons, Nelson, and Simonsohn, 2011). In some ways, however, these are secondary issues. FPA scholars do not simply take it for granted that a result obtained in a laboratory will be applicable to research in foreign policy, which is important given the WEIRD bias of cognitive psychology.

Of greater concern than the question of external validity is the disjuncture between testing theories by using experiments versus testing them using evidence generated by particular individuals in historical cases. Psychology experiments looking at average treatment effects, or the difference between control and treatment groups used in experiments. A statistically significant difference between groups does not mean that all (or even most) individuals in those groups behaved as the theory being tested expects. For example, Tversky and Kahneman (1981, p. 454) note that prospect theory does not apply universally, and more recent work has shown that personal attributes such as occupying a position of power can offset the cognitive effects of loss (Renshon, 2015). Not only then must researchers pay careful attention to how closely the 
experimental context approximates the "real world" in which decision-makers evaluate and implement foreign policies; they should also expect that a certain number of individuals in their case studies will not conform to general psychological findings, even if one assumes the replicability of the findings from which the study draws. Readers should thus be suspicious of case studies in which all decision-makers are portrayed as conforming to a particular cognitive theory.

Another important methodological issue of importance is interaction is the variability of effect strength. Even for theories that have been thoroughly replicated via experiments, the strength of a treatment effect on decision-making may vary considerably between studies and individuals (Krebs and Rapport, 2012, p. 541). This may partially be due to unidentified background conditions that exist even in controlled studies, such as individual characteristics or recent events known to most members of a treatment group, which affect how they interpret and act upon information provided in an experiment. Such effects are even harder to account for in case studies than in experiments.

Given that numerous actors may not behave as cognitive theories expect them to in cases of foreign policymaking, and that the extent to which actors behave as theories predict will vary from case to case and even across time amongst single individuals, should scholars who do cognitive FPA using case studies abandon the idea that their findings will be "scientific"? If one defines science as the discovery of law-like regularities explicable by a general theory, than the answer may be yes. However, there are other models of scientific knowledge production available. FPA scholars using cognitive theory could consider Elster's (1998) invocation of “causal mechanisms" as an alternative. Elster (1998, p. 45) defines mechanisms as "frequently occurring and easily recognizable causal patterns that are triggered under generally unknown 
conditions or with indeterminate consequences." He elaborates that controlled experiments can reveal which causal factors are sufficient to produce some outcome of interest, but in uncontrolled environments like the foreign policy realm it is rare that the causal factors at work in the lab are not partially offset or moderated by other events (1998, p. 51). Cognitive mechanisms may thus be useful for explaining foreign policy outcomes, though not necessarily predicting them. Accepting this premise would encourage cognitively-oriented FPA scholars to treat their research as akin to the "historical sciences" like geology and evolutionary biology, where the goal of research is to elaborate the process by which different mechanisms interacted contingently to produce a specific result (Gaddis, 1996, p. 39). Such a framework would situate cognitive work comfortably within the rest of FPA, where case-specific detail is more the norm than parsimonious general theory (Hudson, 2005, pp.4-5). 


\section{References}

Adcock, R., and Collier, D. (2001). "Measurement Validity: A Shared Standard for Qualitative and Quantitative Research.” American Political Science Review 95(3): 529-546.

Allison, G.T. (1971). Essence of Decision: Explaining the Cuban Missile Crisis (Boston: Little, Brown).

Axelrod, R., ed. (1976). Structure of Decision: The Cognitive Maps of Political Elites (Princeton, NJ: Princeton University Press).

Bar-Tal, D., and Teichman, Y. (2005). Stereotypes and Prejudice in Conflict: Representations of Arabs in Israeli Jewish Society (Cambridge: Cambridge University Press).

Baumeister, R.F., Bratslavsky, E., Finkenauer, C., and Vohs, K.D. (2001). "Bad Is Stronger Than Good." Review of General Psychology 5(4): 323-370.

Beasley, R.K., and Kaarbo, J. (2014). "Explaining Extremity in the Foreign Policies of Parliamentary Democracies.” International Studies Quarterly 58(4): 729-740.

Beasley, R.K., Kaarbo, J., Hermann, C.F., and Hermann, M.G. (2001). "People and Processes in Foreign Policymaking: Insights from Comparative Case Studies." International Studies Review 3(2): 217-250.

Bendor, J., and Hammond, T.H. (1992). "Rethinking Allison's Models.” American Political Science Review 86(2): 301-322.

Bless, H. (2000). "The Interplay of Affect and Cognition: The Mediating Role of General Knowledge Structures." In Forgas, J.P. (ed.), Feeling and Thinking: The Role of Affect in Social Cognition (New York: Cambridge University Press, 2000), 201-222.

Byman, D.L., and Pollack, K.M. (2001). "Let Us Now Praise Great Men: Bringing the Statesman Back In.” International Security 25(4): 107-146.

Eagly, A.H., and Chaiken, S. (1993). The Psychology of Attitudes (London: Harcourt Brace Jovanovich College Publishers).

Elster, J. (1998). “A Plea for Mechanisms.” In Hedstrom, P. and Swedberg, R. (eds.), Social Mechanisms: An Analytical Approach to Social Theory (New York: Cambridge University Press), 45-73.

Etheredge, L.S. (1985). Can Governments Learn? American Foreign Policy and Central American Revolutions (New York: Pergamon).

Farnham, B.R. (2000). Roosevelt and the Munich Crisis: A Study of Political Decision-Making (Princeton, NJ: Princeton University Press). 
Festinger, L. (1957). A Theory of Cognitive Dissonance (Stanford, CA: Stanford University Press).

Fiedler, K. (2000). "Toward an Integrative Account of Affect and Cognition Phenomena Using the BIAS Computer Algorithm.” In Forgas, Feeling and Thinking, 223-252.

Forgas, J.P. (1995). "Mood and Judgment: The Affect Infusion Model (AIM).” Psychological Bulletin 117(1): 39-66.

Fuller, S.R, and Aldag, R.J. (1997). "Challenging the Mindguards: Moving Small Group Analysis beyond Groupthink.” In 't Hart, P., Stern, E.K., and Sundelius, B. (eds.), Beyond Groupthink: Political Group Dynamics and Foreign Policy-Making (Ann Arbor, MI: University of Michigan Press), 55-94.

Gaddis, J.L. (1996). "History, Science, and the Study of International Relations." In Woods, N. (ed.), Explainining International Relations since 1945 (Oxford: Oxford University Press), 32-48.

Garrison, J. (2001). "Framing Foreign Policy Alternatives in the Inner Circle: The President, His Advisors, and the Struggle for the Arms Control Agenda.” Political Psychology 22(4): 775-807.

Gartner, S.S. (1999). Strategic Assessment in War (New Haven, CT: Yale University Press).

George, A.L. (1969). “The 'Operational Code': A Neglected Approach to the Study of Political Leaders and Decision-Making.” International Studies Quarterly 13(2): 190-222.

George, A.L. (1972). "The Case for Multiple Advocacy in Making Foreign Policy." American Political Science Review 66(3): 751-785.

George, A.L., and George, J.L. (1956). Woodrow Wilson and Colonel House: A Personality Study (New York: Dover).

George, A.L., and Stern, E.K. (2002). "Harnessing Conflict in Foreign Policy Making: From Devil's to Multiple Advocacy." Presidential Studies Quarterly 32(3): 484-505.

Glaser, C.L. (1997). “The Security Dilemma Revisited.” World Politics 50(1): 171-201.

Goldgeier, J.M., and Tetlock, P.E. (2001). "Psychology and International Relations Theory." Annual Review of Political Science 4: 67-92.

Greenberg, J., Solomon, S., and Pyszczynski, T. (1997). "Terror Management Theory of SelfEsteem and Cultural Worldviews: Empirical Assessments and Conceptual Refinements." In Zanna, M.P. (ed.), Advances in Experimental Social Psychology, Vol. 29 (San Diego, CA: Academic Press), 61-139. 
Fischhoff, B. (1975). "Hindsight Does Not Equal Foresight: The Effect of Outcome Knowledge on Judgment under Uncertainty." Journal of Experimental Psychology: Human Perception and Performance 1(3): 288-299.

Hafner-Burton, E.M., Hughes, D.A., and Victor, D.G. (2013). "The Cognitive Revolution and the Political Psychology of Elite Decision Making." Perspectives on Politics 11(2): 368-386.

Hall, T., and Yarhi-Milo, K. (2012). “The Personal Touch: Leaders' Impressions, Costly Signaling, and Assessments of Sincerity in International Affairs." International Studies Quarterly 56(3): 560-573.

Hall, T.H., and Ross, A.A. (2015). “Affective Politics after 9/11.” International Organization 69(4): 847-879.

Hammack, P.L., and Pilecki, A. (2012). "Narrative as a Root Metaphor for Political Psychology.” Political Psychology 33(1): 75-103.

Hammond, K.R. (2000). Judgments under Stress (New York: Oxford University Press).

Hemmer, C., and Katzenstein, P.J. (2002). "Why Is There No NATO in Asia? Collective Identity, Regionalism, and the Origins of Multilateralism." International Organization 56(3): 575-607.

Henrich, J., Heine, S., and Norenzayan, A. (2010). "The Weirdest People in the World?" Behavioral and Brain Sciences 33(2-3): 61-83.

Herek, G.M., Janis, I.L., and Huth, P. (1987). "Decision Making during International Crises: Is Quality of Process Related to Outcome?” Journal of Conflict Resolution 31(2): 203-226.

Hermann, C.F. (1990). "Changing Course: When Governments Choose to Redirect Foreign Policy.” International Studies Quarterly 34(1): 3-21.

Hermann, C.F., Stein, J.G., Sundelius, B., and Walker, S.G. (2001). "Resolve, Accept, or Avoid: Effects of Group conflict on foreign policy decisions. International Studies Review, 3(2), 133168.

Hermann, M.G. (1986). "Ingredients of Leadership.” In Hermann, M.G. (ed.), Political Psychology: Contemporary Problems and Issues (San Francisco: Jossey-Bass), 167-192.

Hermann, M.G. (2001). "How Decision Units Shape Foreign Policy: A Theoretical Framework," International Studies Review 3(2): 47-81.

Hermann, M.G., and Hermann, C.F. (1989). "Who Makes Foreign Policy Decisions and How: An Empirical Inquiry.” International Studies Quarterly 33(4): 361-387. 
Hermann, M.G., and Kegley Jr., C.W. (1995). "Rethinking Democracy and International Peace: Perspectives from Political Psychology.” International Studies Quarterly 39(4): 511-533.

Hermann, M.G., Preston, T., Korany, B., and Shaw, T.M. (2001). "Who Leads Matters: The Effects of Powerful Individuals.” International Studies Review 3(2): 83-131.

Herrmann, R.K. (1985). "Analyzing Soviet Images of the United States: A Psychological Theory and Empirical Study.” Journal of Conflict Resolution 29(4): 665-697.

Herrmann, R.K. (1986). “The Power of Perceptions in Foreign-Policy Decision Making: Do Views of the Soviet Union Determine the Policy Choices of American Leaders?" American Journal of Political Science 30(4): 841-875.

Herrmann, R.K., and Choi, J.K. (2007). "From Prediction to Learning: Opening Experts' Minds to Unfolding History." International Security 31(4): 132-161.

Holmes, M. (2013). "The Force of Face-to-Face Diplomacy: Mirror Neurons and the Problem of Intentions." International Organization 67(4): 829-861.

Holsti, K.J. (1970). "National Role Conceptions in the Study of Foreign Policy." International Studies Quarterly 14(3): 233-309.

Holsti, O.R. (1962). “The Belief System and National Images: A Case Study.” Journal of Conflict Resolution 6(3): 244-252.

Horowitz, M.C., and Stam, A.C. (2014). "How Prior Military Experience Influences the Future Militarized Behavior of Leaders.” International Organization 68(3): 527-559.

Hudson, V.M. (2005). "Foreign Policy Analysis: Actor-Specific Theory and the Ground of International Relations." Foreign Policy Analysis 1(1): 1-30.

Hymans, J.E.C. (2006). The Psychology of Nuclear Proliferation: Identity, Emotions, and Foreign Policy (Cambridge: Cambridge University Press).

Jahoda, G. (1999). Images of Savages: Ancient Roots of Modern Prejudice in Western Culture (New York: Routledge).

James, W. (1981 [1890]). The Principles of Psychology (Cambridge, MA: Harvard University Press).

Janis, I.L. (1972). Victims of Groupthink: A Psychological Study of Foreign-Policy Decisions and Fiascoes (Boston: Houghton Mifflin).

Jervis, R. (1970). The Logic of Images in International Relations (Princeton, NJ: Princeton University Press). 
Jervis, R. (1976). Perception and Misperception in International Politics (Princeton, NJ: Princeton University Press).

Jervis, R. (2006). “Understanding Beliefs.” Political Psychology 27(5): 641-663.

Jervis, R. (2013). “Do Leaders Matter and How Would We Know?” Security Studies 22(2): 153179.

Johnson, D.D.P. (2004). Overconfidence and War (Cambridge, MA: Harvard University Press).

Johnson, D.D.P., and Tierney, D. (2011). "The Rubicon Theory of War: How the Path to Conflict Reaches the Point of No Return.” International Security 36(1): 7-40.

Kaarbo, J. (2008). "Coalition Cabinet Decision Making: Institutional and Psychological Factors." International Studies Review 10(1): 57-86.

Kahneman, D., and Tversky, A. (1979a). "Intuitive Prediction: Biases and Corrective Procedures.” TIMS Studies in Management Science, 12: 313-327.

Kahneman, D., and Tversky, A. (1979b). "Prospect Theory: An Analysis of Decision under Risk.” Econometrica: Journal of the Econometric Society 47(2): 263-291.

Kahneman, D., and Tversky, A. (1984). "Choices, Values, and Frames.” American Psychologist 39(4): 341-350.

Karau, S.J., and Kelly, J.R. (1992). “The Effects of Time Scarcity and Time Abundance on Group Performance Quality and Interaction Process." Journal of Experimental Social Psychology 28(6): 542-571.

Kelman, H.C., ed. (1965). International Behavior: A Social-Psychological Analysis (New York: Holt, Rinehart and Winston).

Khong, Y.F. (1992). Analogies at War: Korea, Munich, Dien Bien Phu, and the Vietnam Decisions of 1965 (Princeton, NJ: Princeton University Press).

Koopman, C., Snyder, J., and Jervis, R. (1990). "Theory-Driven versus Data-Driven Assessment in a Crisis: A Survey of International Security Readers." Journal of Conflict Resolution 34(4): 694-722.

Kramer, R.M. (1998). "Revisiting the Bay of Pigs and Vietnam Decisions 25 Years Later." Organizational Behavior and Human Decision Processes 73(2/3): 236-271.

Krebs, R.R., and Rapport, A. (2012). "International Relations and the Psychology of Time Horizons.” International Studies Quarterly 56(3): 530-543.

Larson, D.W. (1994). "The Role of Belief Systems and Schemas in Foreign Policy DecisionMaking.” Political Psychology 15(1): 17-33. 
Lasswell, H.D. (1930). Psychopathology and Politics (Chicago: University of Chicago Press).

Lau, R.R., and Levy, J.S. (1998). "Contributions of Behavioural Decision Theory to Research in Political Science.” Applied Psychology: An International Review 47(1): 29-44.

Le Prestre, P.G., ed. (1997). Role Quests in the Post-Cold War Era: Foreign Policies in Transition (Montreal: McGill-Queen's University Press).

Lebovic, J.H. (1995). "How Organizations Learn: U.S. Government Estimates of Foreign Military Spending.” American Journal of Political Science 39(4): 835-863.

Leites, N. (1951). The Operational Code of the Politburo (New York: McGraw Hill).

Levy, J.S. (1992). “An Introduction to Prospect Theory.” Political Psychology 13(2): 171-186.

Levy, J.S. (1994). "Learning and Foreign Policy: Sweeping a Conceptual Minefield." International Organization 48(2): 279-312.

Maoz, Z. (1990). "Framing the National Interest: The Manipulation of Foreign Policy Decisions in Group Settings." World Politics 43(1): 77-110.

March, J. (1978). "Bounded Rationality, Ambiguity, and the Engineering of Choice.” Bell Journal of Economics 9(2): 587-608.

Marcus, G.E., Sullivan, J.L., Theiss-Morse, E., and Wood, S.L. (1995). With Malice Toward Some: How People Make Civil Liberties Judgments (Cambridge: Cambridge University Press).

McDermott, R. (1998). Risk-Taking in International Politics: Prospect Theory in American Foreign Policy (Ann Arbor, MI: University of Michigan Press).

McDermott, R. (2004). "The Feeling of Rationality: The Meaning of Neuroscientific Advances for Political Science.” Perspectives on Politics 2(4): 691-706.

Meade, E.E., and Stasavage, D. (2008). "Publicity of Debate and the Incentive to Dissent: Evidence from the U.S. Federal Reserve.” The Economic Journal 118(528): 695-717.

Mercer, J. (1995). Reputation and International Politics (Ithaca, NY: Cornell University Press).

Mercer, J. (2005). "Prospect Theory and Political Science." Annual Review of Political Science 8: 1-21.

Mercer, J. (2010). “Emotional Beliefs.” International Organization 64(1): 1-31.

Mercer, J. (2013). "Emotion and Strategy in the Korean War." International Organization 67(2): 221-252. 
Mintz, A. (2004). "How Do Leaders Make Decisions? A Poliheuristic Perspective." Journal of Conflict Resolution 48(1): 3-13.

Mintz, A. (2007). “Why Behavioral IR?” International Studies Review 9(1): 157-162.

Mintz, A., and Geva, N. (1997). "The Poliheuristic Theory of Foreign Policy Decisionmaking." In Geva, N., and Mintz, A. (eds.), Decisionmaking on War and Peace: The Cognitive-Rational Debate (London: Lynne Rienner), 81-102.

Mintz, A., Redd, S.B., and Vedlitz, A. (2006). "Can We Generalize from Student Experiments to the Real World in Political Science, Military Affairs, and International Relations?" Journal of Conflict Resolution 50(5): 757-776.

Neustadt, R.E. and May, E.R. (1986). Thinking in Time: The Uses of History for Decisionmakers (New York: The Free Press).

Nickerson, R.S. (1998). “Confirmation Bias: A Ubiquitous Phenomenon in Many Guises.” Review of General Psychology 2(2): 175-220.

Pashler, H., and Wagenmakers, E. (2012). "Editors' Introduction to the Special Section on Replicability in Psychological Science: A Crisis of Confidence?" Perspectives on Psychological Science 7(6): 528-530.

Patterson, M., and Monroe, K.R. (1998). "Narrative in Political Science.” Annual Review of Political Science 1: 315-331.

Pillar, P. (2011). Intelligence and U.S. Foreign Policy: Iraq, 9/11, and Misguided Reform (New York: Columbia University Press.)

Rapport, A. (2015). Waging War, Planning Peace: U.S. Noncombat Operations and Major Wars (Ithaca, NY: Cornell University Press).

Rathbun, B.C. (2007). "Hierarchy and Community at Home and Abroad: Evidence of a Common Structure of Domestic and Foreign Policy Beliefs in American Elites." Journal of Conflict Resolution 51(3): 379-407.

Rathbun, B.C. (2014) Diplomacy's Value: Creating Security in 1920s Europe and the Contemporary Middle East (Ithaca, NY: Cornell University Press).

Reiter, D. (1996). Crucible of Beliefs: Learning, Alliances, and World Wars (Ithaca, NY: Cornell University Press).

Renshon, J. (2008). "Stability and Change in Belief Systems: The Operational Code of George W. Bush from Governor to Second-Term President." Journal of Conflict Resolution 52(6): 820849. 
Renshon, J. (2015). "Losing Face and Sinking Costs: Experimental Evidence on the Judgment of Political and Military Leaders.” International Organization 69(3): 659-695.

Rieskamp, J., and Hoffrage, U. (2008). "Inferences under Time Pressure: How Opportunity Costs Affect Strategy Selection.” Acta Psychologica 127(2): 258-276.

Rokeach, M. (1973). The Nature of Human Values (New York: Free Press).

Rosati, J.A. (2000). "The Power of Human Cognition in the Study of World Politics." Internaional Studies Review 2(3): 45-75.

Ross, L. (1977). "The Intuitive Psychologist and His Shortcomings: Distortions in the Attribution Process." In Berkowitz, L. (ed.), Advances in Experimental Social Psychology, Vol. 10 (New York: Academic Press), 173-220.

Saunders, E.N. (2011). Leaders at War: How Presidents Shape Military Interventions (Ithaca, NY: Cornell University Press).

Saunders, E.N. (forthcoming). "No Substitute for Experience: Presidents, Advisers, and Information in Group Decision-Making." International Organization.

Schafer, M. (2000). "Issues in Assessing Psychological Characteristics at a Distance: An Introduction to the Symposium.” Political Psychology 21(3): 511-527.

Schafer, M., and Crichlow, S. (2010). Groupthink versus High-Quality Decision Making in International Relations (New York: Columbia University Press).

Schafer, M., and Walker, S.G., eds. (2006). Beliefs and Leadership in World Politics: Methods and Applications of Operational Code Analysis (New York: Palgrave Macmillan).

Schelling, T. (1966). Arms and Influence (New Haven, CT: Yale University Press).

Shimko, K.L. (1994). "Metaphors and Foreign Policy Decision Making.” Political Psychology 15(4): 655-671.

Simmons, J.P., Nelson, L.D., and Simonsohn, U. (2011). "False-Positive Psychology: Undisclosed Flexibility in Data Collection and Analysis Allows Presenting Anything as Significant." Psychological Science 20(10): 1-8.

Simon, H.A. (1972). “Theories of Bounded Rationality.” Decision and Organization 1(1): 161176.

Simon, H.A. (1985). "Human Nature in Politics: The Dialogue of Psychology with Political Science.” American Political Science Review 79(2): 293-304.

Snyder, R.C., Bruck, H.W., and Sapin, B. (1962). Foreign Policy Decision-Making (New York: Free Press). 
Sprout, H., and Sprout, M. (1965). The Ecological Perspective on Human Affairs (Princeton, NJ: Princeton University Press).

Stasser, G., and Titus, W. (2003). "Hidden Profiles: A Brief History.” Psychological Inquiry 14(3/4): 304-313.

Stein, J.G. (1994). "Political Learning by Doing: Gorbachev as Uncommitted Thinker and Motivated Learner.” International Organization 48(2): 155-183.

Stein, J.G. (2002). "Political Learning and Political Psychology: A Question of Norms.” In Monroe, K.R. (ed.), Political Psychology (London: Lawrence Erlbaum Associates) 107-117.

Steinbruner, J.D. (1974). The Cybernetic Theory of Decision: New Dimensions of Political Analysis (Princeton, NJ: Princeton University Press).

Stern, E. (1997). "Crisis and Learning: A Conceptual Balance Sheet." Journal of Contingencies and Crisis Management 5(2): 69-86.

Stern, E. (2004). "Contextualizing and Critiquing the Poliheuristic Theory." Journal of Conflict Resolution 48(1): 105-126.

Streich, P., and Levy, J.S. (2007). "Time Horizons, Discounting, and Intertemporal Choice." Journal of Conflict Resolution 51(2): 199-226.

Suedfeld, P., and Tetlock, P. (1977). "Integrative Complexity of Communications in International Crises.” Journal of Conflict Resolution 21(1): 169-184.

Sweller, J. (1988). "Cognitive Load during Problem Solving: Effects on Learning." Cognitive Science 12(2): 257-285.

Sylvan, D.A., and Voss, J., eds. (1998) Problem Representation in Foreign Policy Decision Making (Cambridge: Cambridge University Press).

Tetlock, P.E. (1985). "Accountability: The Neglected Social Context of Judgment and Choice." Research in Organizational Behavior 7(1): 297-332.

Tetlock, P.E. (1999). "Theory-Driven Reasoning about Plausible Pasts and Probable Futures in World Politics: Are We Prisoners of Our Preconceptions?” American Journal of Political Science 43(2): 335-366.

Tetlock, P.E. (2005). Expert Political Judgment: How Good Is It? How Can We Know? (Princeton, NJ: Princeton University Press). 
Tetlock, P.E., Peterson, R.S., McGuire, C., Chang, S.J., and Feld, P. (1992). “Assessing Political Group Dynamics: A Test of the Groupthink Model." Journal of Personality and Social Psychology 63(3): 403-425.

Trope, Y., and Liberman, N. (2003). “Temporal Construal.” Psychological Review 110(3): 403421.

Tversky, A., and Kahneman, D. (1974). “Judgment under Uncertainty: Heuristics and Biases.” Science, 185(4157): 1124-1131.

Tversky, A., and Kahneman, D. (1981). "The Framing of Decisions and the Psychology of Choice." Science 211: 453-458.

Vertzberger, Y. (1984). "Bureaucratic-Organizational Politics and Information Processing in a Developing State.” International Studies Quarterly 28(1): 69-95.

Vertzberger, Y. (1990). The World in Their Minds: Information Processing, Cognition, and Perception in Foreign Policy Decisionmaking (Stanford, CA: Stanford University Press).

Vertzberger, Y.Y.I. (1986). "Foreign Policy Decisionmakers as Practical-Intuitive Historians: Applied History and Its Shortcomings." International Studies Quarterly 30(2): 223-247.

Vertzberger, Y.Y.I (1998). Risk Taking and Decisionmaking: Foreign Military Intervention Decisions (Stanford, CA: Stanford University Press).

Walker, S.G., ed. (1987). Role Theory and Foreign Policy Analysis (Durham, NC: Duke University Press).

Walker, S.G., Schafer, M., and Young, M.D. (1998). "Systematic Procedures for Operational Code Analysis: Measuring and Modeling Jimmy Carter's Operational Code." International Studies Quarterly 42(1): 175-189.

Welch, D.A. (1992). "The Organizational Process and Bureaucratic Politics Paradigms: Retrospect and Prospect.” International Security 17(2): 112-146.

Wendt, A. (1998). "On Constitution and Causation in International Relations." Review of International Studies 24(5): 101-118.

Yarhi-Milo, K. (2014). Knowing the Adversary: Leaders, Intelligence, and Assessment of Intentions in International Relations (Princeton, NJ: Princeton University Press). 


\section{Further Reading}

McDermott, R. (2004). Political Psychology in International Relations (Ann Arbor, MI: University of Michigan Press).

Mintz, A., and DeRouen Jr., K. (2010). Understanding Foreign Policy Decision Making (Cambridge: Cambridge University Press).

Newell, B.R., Lagnado, D.A., and Shanks, D.R. (2015). Straight Choices: The Psychology of Decision Making, 2nd edition (New York: Psychology Press).

Renshon, S.A., and Larson, D.W., eds. (2003). Good Judgment in Foreign Policy: Theory and Application (Lanham, MD: Rowman and Littlfield).

Walker, S.G., Malici, A., and Schafer, M., eds. (2011). Rethinking Foreign Policy Analysis: States, Leaders, and the Microfoundations of Behavioral International Relations (New York: Routledge). 